\title{
Analyzing drivers of renewable energy development in Southeast Asia countries with correlation and decomposition methods
}

\author{
Khuong, Phuong M.; McKenna, Russell; Fichtner, Wolf
}

Published in:

Journal of Cleaner Production

Link to article, DOI:

10.1016/j.jclepro.2018.12.192

Publication date:

2019

Document Version

Peer reviewed version

Link back to DTU Orbit

Citation (APA):

Khuong, P. M., McKenna, R., \& Fichtner, W. (2019). Analyzing drivers of renewable energy development in Southeast Asia countries with correlation and decomposition methods. Journal of Cleaner Production, 213, 710722. https://doi.org/10.1016/j.jclepro.2018.12.192

\section{General rights}

Copyright and moral rights for the publications made accessible in the public portal are retained by the authors and/or other copyright owners and it is a condition of accessing publications that users recognise and abide by the legal requirements associated with these rights.

- Users may download and print one copy of any publication from the public portal for the purpose of private study or research.

- You may not further distribute the material or use it for any profit-making activity or commercial gain

- You may freely distribute the URL identifying the publication in the public portal 


\title{
Analyzing drivers of renewable energy development in Southeast Asia countries with Correlation and Decomposition methods
}

\author{
Phuong M. Khuong, Russell McKenna, Wolf Fichtner
}

\section{Table of Contents}

1. Introduction

2. Renewable energy development and policy analysis

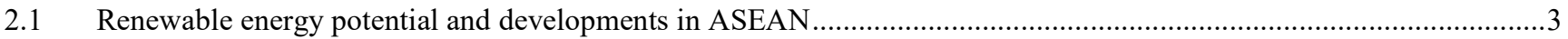

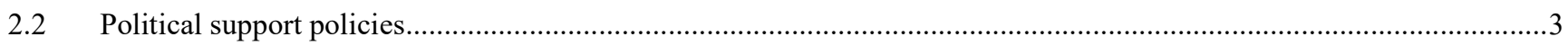

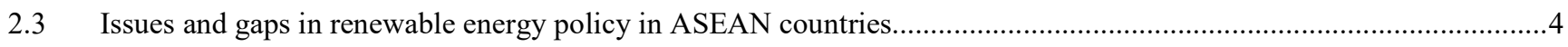

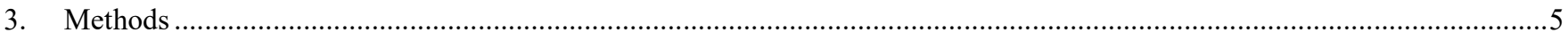

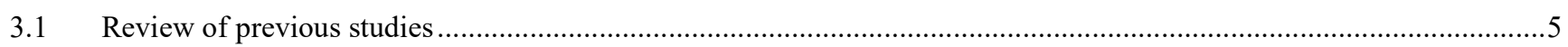

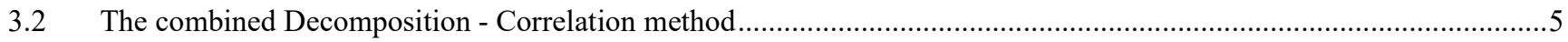

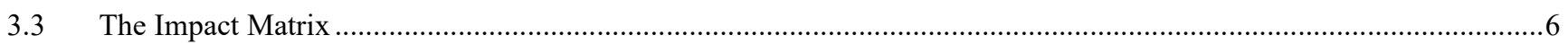

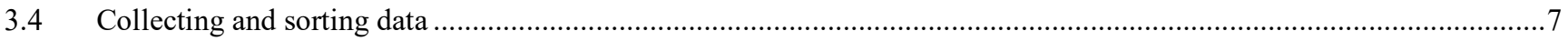

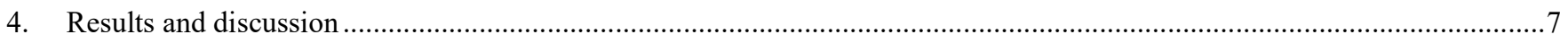

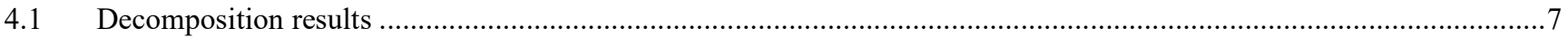

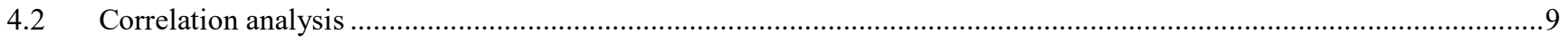

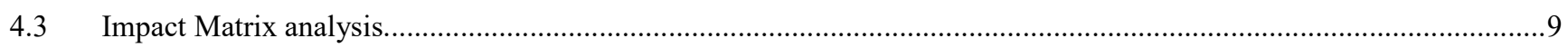

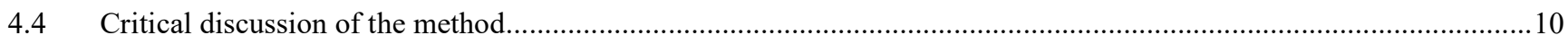

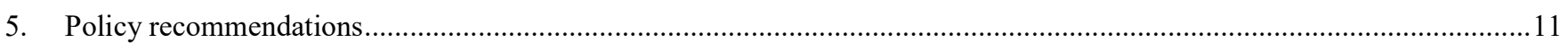

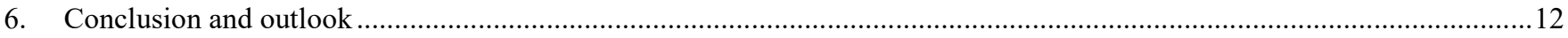

\section{Abstract}

The Association of South East Asian Nations (ASEAN) is a diverse region characterized by rapid economic growth, demographic change and urbanization. The dominance of energy supply from non-renewable resources in the region means that the increasing energy demand has implications for energy security, as well as adverse local and global environmental effects. Climatic conditions in the region are favorable for renewable energy (RE) resources, especially but not only wind and solar technologies. ASEAN countries differ strongly in terms of their national policy frameworks and progress in renewable energy development; the overall target of $23 \%$ renewables by 2025 is very ambitious under current policy frameworks.

This paper identifies a gap between these national policies and local governance, especially in urban areas, which requires attention to ensure future target fulfilment. By employing a new combined Correlation and Decomposition approach at country and city levels, we investigate the determinants of RE expansion and explore the trend drivers in ASEAN countries from 1995 to 2013. An Impact Matrix is developed to position and interpret the relative push (e.g. policy) and pull (e.g. market) impacts on RE development, and to derive policy recommendations for countries and sectors. The results highlight that urban areas should be the focus of RE policy and governance in addition to rural areas. The tremendous impact of economic growth creates a great impetus for renewable energy development, but urbanization is the second pull for renewable energy extensions. 
Since the two effects are located in the first quadrant of the Impact Matrix, if strategists affect these factors, they will create the most powerful incentive for renewable energy growth. This confirms that if the strategic aim is to promote renewable energy market development, through policy and governance measures, the focus should be on urban areas, non-electricity sectors and the demand side.

Keywords-Urbanization effect, Renewable energy, ASEAN, Correlation Decomposition, Governance.

\section{Introduction}

ASEAN is a regional organization comprising ten Southeast Asian countries, characterized by rapid urbanization, industrialization, and an increasingly important role of the urban service sector. Urban population in the region is expected to grow by around 100 million people, rising from 280 million people today to 373 million people by 2030 . ASEAN is recorded as the second fastest developing region in the world, with an average GDP growth rate of 4.8\% in 2016 and 5.1\% in 2017 (IMF - Internation Monetary Fund, OECD 2018), and is predicted to grow faster, by an average 6.3\% per year over the period 2018-2022 (OECD 2018). The changes have occurred historically in megacities and large cities, and nearly 40 percent of ASEAN's GDP growth to 2025 is expected to come from 142 cities with populations between 200,000 and 5 million (The Economist Intelligence Unit 2016). Due to the fact that highly urbanized countries tend to consume more energy, ASEAN governments are experiencing problems in dealing with local energy shortages (especially power shortages in the Philippines and Vietnam) and GHG emissions from highdensity population (ASEAN 50 ${ }^{\text {th }}$ year anniversary conference's reports, (ASEAN Centre for Energy (ACE) 2018)).

Aware of the challenges and opportunities presented by rapid urban growth, ASEAN Member States engage in sustainable development and regional integration is carried out by the Sustainable ASEAN Socio-cultural community Blueprint 2025 . The agreement encourages renewable energy usage to partly lessen the energy supply burden and reduce the environmental impacts of urban expansion. Solar and wind power technologies are predicted as potential renewable energies for urban areas. Benefits due to lower levels of air pollution and $\mathrm{CO} 2$ emissions from the expected renewable energy development could potentially result in savings equal to between $0.2 \%$ and $1.0 \%$ of ASEAN's GDP in 2025 (IRENA and ASEAN Centre for Energy (ACE) 2016). However, after intensive support from the governments, renewable energy capacity (excluding large hydro power and biomass firewood) in the region has not increased as expected. The renewable energy production accounted for only 9.4 percent of total primary energy supplies by 2014 . It is expected to reach only 17 percent approximately by 2025 , while the original target share is set at 23\% (ASEAN Centre for Energy (ACE) 2017).

The most significant challenges to developing renewable energy in the region have been identified as geographical and technical conditions, inadequate regulatory frameworks, persistence of subsidies on conventional energy sources, import tariffs on renewable energy goods, and the lack of public awareness and support (Arie Rahmadi et al. 2017). ASEAN countries are taking important initial steps, but ample opportunities remain for improving the overall renewable energy policy and regulatory environment (IRENA 2018). Since urbanization mostly happens dramatically in megacities, cities' governance would play crucial role in enhancing renewable energy usage. Based on their own features, cities could create different and unique programs in the field of energy management, climate change adaptation, improved resource efficiency, and renewable energy planning. This lack of policy integration means that these types of complicated, interconnected issues cannot be appropriately addressed, and is resulting in ineffective and inefficient policy deployment (Runhaar, Driessen and Soer, 2009).

To fill this gap, this paper intends to provide evidence of the importance of governance policy, interaction by common target groups and combining action plans for policy-makers in establishing renewable energy policy. All of these will be addressed by answering three arising scientific questions for renewable energy policy at national and city levels in ASEAN. The first question is why urban areas and cities play an important role in encouraging renewable energy extensions. The second question is where urban policy and urban governance can be most effective. Lastly, the third question is how to review and revise renewable energy policy in the light of constantly-varying influencing factors.

The paper is structured as follows. Section 2 assesses past and possible future renewable energy developments, before discussing policy-supporting schemes to reveal the policy problems and the lack of scientific research in this field. Section 3 addresses solutions from previous studies related to determining the drivers of renewable energy extension, in order to develop a new decision-support method for policy-makers. By analyzing the uncovered points in these studies, this paper proposes a method that combines decomposition and correlation methods to identify policy target groups and focus. The results and discussion are presented in section 4, while section 5 derives policy recommendations and section 6 contains conclusions and an outlook.

\section{Renewable energy development and policy analysis}

The section analyzes the main reasons for renewable energy development in ASEAN. The issues are highlighted and discussed based on theoretical and practical arguments. Since there is a lack of scientific studies in the region, we had to review many regional 
reports of international (as IEA, IRENA), regional (ACE - ASEAN Centre of Energy), national and Banking (ADB, World Bank) research organizations and compared different reports to verify the accuracy and derive conclusions.

\section{$2.1 \quad$ Renewable energy potential and developments in ASEAN}

ASEAN is richly endowed with diverse renewable energy sources such as wind and solar in the whole region (ASEAN Centre for Energy (ACE) 2017). The significant realizable potential of wind power in Indonesia, Thailand, Vietnam and the Philippines is approximately $63 \mathrm{TWh}, 57 \mathrm{TWh}, 45 \mathrm{TWh}$ and $22 \mathrm{TWh}$ respectively (International Energy Agency 2010). Due to being located close to the equator, the countries receive high daily insolation of $4-7 \mathrm{kWh} / \mathrm{m}^{2}$. Consequently, the technical potential of solar power is evaluated at $65 \mathrm{GW}$ in Cambodia, $10 \mathrm{GW}$ in Laos, $26 \mathrm{GW}$ in Myanmar, $33 \mathrm{GW}$ in Thailand and 25 GW in Vietnam (Asian Development Bank 2015; International Energy Agency 2010). The rapid growth of renewable energy technology (Terziotti et al. 2012; Ishugah et al. 2014) and a subsequent decline in renewable energy costs (Wei et al. 2014; IRENA 2018) could lead urban neighborhoods to move away from traditional energy resources and centralized utility models to decentralized energy supply.

Renewable energy accounted for $26 \%$ in total primary energy supply (TPES) in 2016, but is dominated by traditional biomass (20\%) and hydropower (3\%) (Southeast Asia Energy Outlook - OCED 2017). Due to the concern about the environment damages due to solid biomass and large hydropower, some ASEAN countries excluded large-scale hydropower from their renewable energy target. However, all of them excluded the traditional form of firewood in their renewable energy supporting schemes since 2015 (Table 1). The remainder, consisting of non-hydro renewable, accounts for a relatively limited percentage in total demand, less than $1 \%$ of TPES.

Comparing the installed capacity of all renewable energy types corresponding with their targets in each country (Table 1) shows the large gaps between expectation and reality of ASEAN renewable energy development. Except for Malaysia, where the total renewable energy installed reaches $65 \%$ of their 2020 target (mostly coming from increasing hydro with $91 \%$ ), the other countries are struggling in promoting renewable energy, especially Cambodia, Laos and Myanmar.

Solar and wind are considered the most promising form of renewable energy in general, and urban areas particularly in ASEAN (Ismail et al. 2015; Singh and Banerjee 2015). However, progress towards reaching these targets seems to be slow. Except for Thailand, by the end of 2015 the total installed capacity of solar arrived at $73 \%$ of the expected capacity in the 2020 target. Overall, the shares of installed capacity for wind and solar, however, accounted for only $1 \%$ and $2 \%$, respectively, of total existing renewable energy capacity by the end of 2016.

Comparing the development of solar and wind with other types of renewables between 2015 and 2016, reveals strong growth in ASEAN. While hydropower increased the installed capacity by $939 \mathrm{MW}$, corresponding to a $3.8 \%$ annual growth rate, wind extended by $297 \mathrm{MW}$, equaling a 37\% annual growth rate, and solar PV experienced a strong increase by $1621 \mathrm{MW}$, amounting to a $88 \%$ annual growth rate. If this trend continues, solar could become the leader of ASEAN renewable energy developments in the near future.

\section{Table 1. about here}

\subsection{Political support policies}

In recent years, ASEAN governments as a whole as well as individual countries have created many schemes based on their renewable energy development targets to develop renewable energy in the region. Table 2 provides an overview of renewable energy policy in ASEAN by the end of 2017.

The first five columns in Table 2 summarize the government policy. National programme indicates a promoting programme for different types of renewable energy such as solar heat, solar power, wind, geothermal and biofuel. Among ASEAN countries, Thailand is the only one having a supporting program for solar heat; the other countries rather focus on solar power, wind and biofuels. With verified high geothermal potentials, Indonesia and the Philippines are the only countries with added programs for developing it.

As leaders in the region for committed renewable energy, Indonesia has completed guidelines for biomass, biogas, small hydropower and geothermal at the end of 2016, while Malaysia completed guidelines for small hydropower and solar implementation. The Philippines and Vietnam finalized their guidelines for solar power in early 2017 (ASEAN Centre for Energy (ACE) 2017; IRENA 2018; IEA - International Energy Agency 2017). Although each country has different policy from each other, they still collaborate. One such joint effort was the common target and roadmap called Remap Options for a Clean, Sustainable and Prosperous Future, published in 2016 (IRENA and ASEAN Centre for Energy (ACE) 2016). This roadmap provided a breakdown of renewable energy potential by sector and source, and established guidelines to achieve all targets.

Considering investment in renewable in the seventh column, ASEAN mostly invests in renewable energy in the power sector (excluding large hydropower) with a very limited amount of over 2.6 billion USD in 2016, which equals to $1 \%$ of global and $2 \%$ of Asia-Pacific investment (BNEF, 2017). Investment in solar PV increased dramatically in Thailand with 3.8 USD billion in 2015. 
In addition, the investment trend has increased greatly in Singapore and Indonesia, but has decreased in the Philippines, Malaysia and Vietnam (IRENA 2018). According to IRENA report about Renewable Energy Market Analysis (IRENA 2018), the cost needed to increase the renewable share to reach ASEAN's 23\% target would only be USD 1.9 per MWh of final renewable energy in 2025, which is less expensive than the previous period.

Table 2. about here

The sixth column in Table 2 summarizes R\&D funding in the region. The funding comes from both national budgets as well as international banking budgets such as ADB - Asian Development Bank. Recently, Singapore is leading the R\&D that focuses entirely on solar rooftop deployment, followed by Thailand and the Philippines. The last column specifies the integrated policy between government and governance in ASEAN. Thailand is the first country in ASEAN that implemented governance policy below the government one in 2013, following this is Malaysia with a policy pending approval. It drafts and proposes all policies related to energy, including electric power and renewable energy policies. It is composed of two offices and three departments, which have different responsibilities and missions. However, Thailand has been struggled on ensuring efficient and effective corporate governance, and resolving any potential conflicts of authority at the ministerial and regulatory level.

Combining the progress of renewable energy development in Table 1 and the relevant policy in Table 2 shows that renewable energy extension is closely linked to policy support. There are three different developing situations in the region. The first is slow development of renewable energy in Brunei, Cambodia, Laos, and Myanmar. Secondly, countries with marginal investment and R\&D like Vietnam can reach only $2.3 \%$ of their target. Thirdly, those that are more advanced in expanding renewable energy such as Malaysia, the Philippines, Singapore and Thailand, pay more attention to R\&D and investment, and can on average reach the target ten times faster with $17 \%$ to $37 \%$. The noteworthy progress of Thailand in terms of enhancing solar by fulfilling $72 \%$ of its 2020 target by the end of 2015 is shown in the last column in Table 1, and can be explained by Thai renewable energy policies. Thailand is the only country focusing on solar heating and urban areas with the integration of government and governance policies.

\subsection{Issues and gaps in renewable energy policy in ASEAN countries}

Because of the intimate relationship between renewable energy development and political support in the region, adjusting renewable energy support mechanisms is a key solution to help renewable energy get out of a deadlock situation. Since renewable energy potential is differentiated by geographic location and terrain elevation, local governments with governance policy might play a more important role in increasing the uptake of renewables. They can provide greater understanding of the current and future potential for renewable heating, cooling, electricity and transport biofuels based on their own features. Because of the differentiation of socio-economic, cultural and political situation, local policy makers can invest more wisely and precisely to enhance renewable energy deployment and identify possible benefits for local citizens and businesses (Chimres and Wongwises 2016; Daniel M. Kammen and Deborah A. Sunter 2016; Eskew et al. 2018).

However, urban governance policy is either missing or weak in ASEAN. ASEAN governments released several incentives and policy initiatives at a national level, which mentioned the importance of city governments and governances in working together to support the implementation of renewable energy strategies, policies and programs. In fact, 8 out of 10 countries in ASEAN have no governance policy. Besides, Marquardt (2014) indicated three major obstacles for renewable energy development in ASEAN as a lack of awareness for national intentions among subnational authorities and vice versa, weak capacity on the local level and a lack of consultation during policy formulation.

Some countries consider releasing local policy for renewable energy, but the involvement of governance is still a political bottleneck in the region. In the case of Malaysia, the New Energy Policy released in 2010 mentioned governance roles in the energy transition. A procedure and structure of sustainable development governance are proposed in the Review 2017 of the High-level Polical Forum in Philippines. It is included in the draft law, which is awaiting approval, however, the main challenges are the governance of the energy sector in Malaysia, which is not only fragmented but also incoherent (Yatim et al. 2016).

Thailand was the only country that released a general governance policy in the region in 2013. However, despite the presence of the Alternative Energy Development Plan (AEDP) and its targets, there is no mechanism to ensure that the targets are met and that relevant agencies in the public sector undertake their responsibilities in the most effective manner. Moreover, the permitting procedures are complicated by low transparency (Tongsopit at. el 2015). Thailand's governance in the energy sector is weak, particularly concerning independence, transparency, public participation and accountability (Sirasoontorn et. al. 2017). The Energy Regulatory Commission (ERC) for governance policy in Thailand has been criticized, particularly in the area of autonomy and independence from political interference. 


\section{Methods}

\subsection{Review of previous studies}

Research on the influences on renewable energy consumption most often employs regression and decomposition analysis. Many previous studies build on a nonparametric regression analysis at the sector level as well as indices constructed from a decomposition of this index, e.g. Ang 2005, 2006; Ang et al. 2009; Ang et al. 2004; Ang 2004; Boyd and Roop 2004; Ang et al. 2003; Hoekstra and van den Bergh 2003; Steve Heinen 2013. A regression analysis with dynamic and statistical models was used in most studies in this field until Liu (2009) compared the results between an autoregressive-distributed lag (ARDL) and a factor decomposition model (FDM) in China to show the limitations of the regression method. They concluded that regression methods are limited in multi-tiered analysis, especially when applied to diverging influences on energy use from national sector levels to sectorial levels.

The decomposition method has frequently been utilized in energy-related analysis from the late 1970s until now (Zhang and Ang 2001; Hoekstra and van den Bergh 2003). It has proved to be an effective and powerful tool to explain the changes and impacts that occur in any variables over time or space. In particular, it allows the application of multi-level data to assess the effect of different factors on different energy users. This technique is used to study the impact of changes in product mix on energy consumption. Decomposition can be conducted by two techniques including Structural Decomposition Analysis (SDA) and Index Decomposition Analysis (IDA). While SDA uses input-output data to distinguishing ta large number of specific determinant inputoutput effects mostly in micro scale as sub-sector and companies, IDA uses aggregated data to distingue the effect with macro scale such as sector, multi-sector and national scale (Hoekstra and van den Bergh 2003, Wang et al. 2017)

In assessing the influence of urbanization on energy consumption, Lin et al. (2008) and Liu (2009) suggested to use the decomposition method to separate urbanization effect out of aggregate effect. Following this idea, Wang (2014) applied the structure decomposition method (SDA) to investigate the effects of China's urbanization on residential energy consumption and production energy consumption. He did independent research for household usage and product usage by dividing total energy consumption into residential energy consumption (REC) and production energy consumption (PEC). The results showed different effects of urbanization on PEC, by dividing the study period into three stages. However, the results were limited due to lacking annual input-output data for several sectors in China.

Yang et al. (2016) used the index decomposition method (IDA) to assess the impact of urbanization in renewable energy consumption growth in China by analyzing five effects including energy mix, energy intensity, economic structure, GDP and urbanization effects. However, the calculation only focused on the macroeconomic level. The comparison of urban with other effects on total energy consumption and renewable energy consumption were expressed as weighted averages of effect shares and renewable energy change relatives.

Few previous studies came up with the idea of combined decomposition and regression analyses in the energy literature such as Zhang and Jiang 2016; Shakouri and Khoshnevis Yazdi 2017; Karimu et al. 2017; Nicholas Apergis and Dan Constantin Danuletiu; Saad and Taleb 2017; Metcalf, 2008; Mulder and de Groot, 2012; Sue Wing, 2008. However, the studies mostly focused on energy efficiency advice. For example, Metcalf (2008) and Sue Wing (2008) only focused on energy intensity determinants and trend analysis, respectively, whereas Mulder and de Groot (2012) focused on trend and energy convergence of similar sectors across countries.

\subsection{The combined Decomposition - Correlation method}

Based on the idea of combining the two techniques, this paper intends to take advantage of both methods in measuring the impact of different influencing factors on renewable energy developments. It will disentangle the contributions by comparing them in a multi-level, regional-country-sectorial analysis. The results will show the main driving factors for renewable energy extension and suggest key groups and specific incentives to policy makers in ASEAN.

The method is the combination model of Correlation Analysis and Decomposition Analysis. The model uses a multiplicative model for cross-classified data including regional analysis, cross-country and cross-sector analyses. It employs renewable energy crossclassified by renewable energy types and renewable energy users. The concept of the method is illustrated in Figure 1.

\section{Figure 1. about here}

First, total renewable energy increase is decomposed into the various contributions including adjustment in share of renewable energy consumption in total energy consumption (energy mix effect), changes in sectorial energy intensity (intensity effect), modification of activity composition (structure effect), activity change (activity effect), and especially urbanization changes (urban effect). The total change in renewable energy growth is the result of adding the disparities in indicators of renewable energy resources such as solar, wind, hydro, and biomass. The decomposition analysis allows comparing across countries and sectors. If results show negative values, it means the weighted average impact of a factor is less than 0 . Therefore, the factor has negative 
interaction on renewable energy growth over the considered period and vice versa.

The model exploits the panel data by observing the cross-section of individual sectors over annual periods. The renewable energy changes or effect indicators function is expressed as (for symbols see Table 4):

$$
\Delta \mathrm{RE}_{(\mathrm{i})}=\mathrm{f}\left(\Delta \mathrm{E}_{\mathrm{mix}}, \Delta \mathrm{E}_{\text {int }}, \Delta \mathrm{E}_{\mathrm{str}}, \Delta \mathrm{E}_{\mathrm{act}}, \Delta \mathrm{E}_{\mathrm{ur}}\right)+E_{\text {rsd }} \quad \text { [eq. 1] }
$$

Decomposition equations for sector:

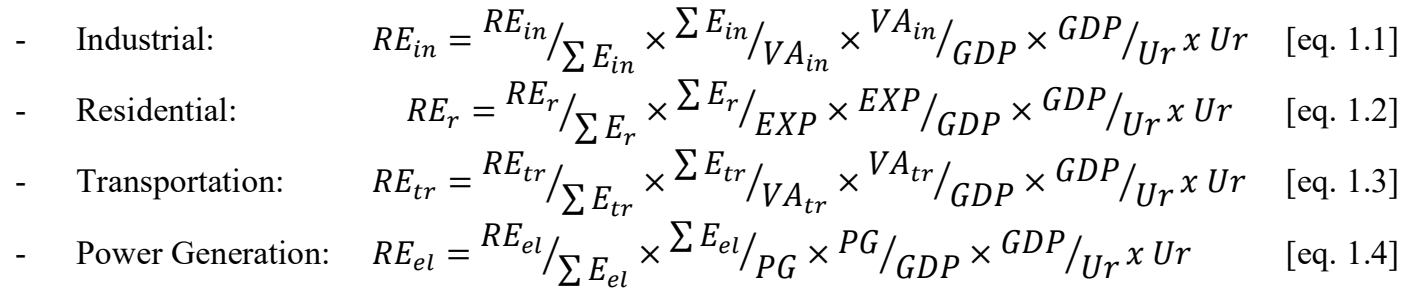

Symbols, detailed equations by sectors and the explanation of the meaning of each indicator are given below in Table 3 and Table 4.

Table 3. about here

Table 4. about here

Subsequently, a Correlation analysis is used to assess the correlation between renewable energy change and its effect indicators. This is a bivariate analysis that measures the strength of association between each combination of two variables. It has the advantage of arbitrary factors, which offer more flexible specifications in the analysis that is not granted by the traditional decomposition methods. The goal of using correlation analysis is to analyze whether two measurement variables co-vary, and to quantify the strength of the relationship between the considered indicator and renewable energy change.

The formula for the sample correlation coefficient is

$r=\frac{\operatorname{Cov}(x, y)}{\sqrt{s_{x}^{2} s_{y}^{2}}} \quad$ [eq. 2]

where $\operatorname{Cov}(\mathrm{x}, \mathrm{y})$ is the covariance of $\mathrm{x}$ and $\mathrm{y}$ defined as

$\operatorname{Cov}(x, y)=\frac{\sum(X-\bar{X})(Y-\bar{Y})}{n-1}$ [eq. 3]

$s_{x}^{2}$ and $s_{y}^{2}$ are the sample variances of $\mathrm{x}$ and $\mathrm{y}$, defined as $s_{x}^{2}=\frac{\sum(X-\bar{X})^{2}}{n-1}$ and $s_{y}^{2}=\frac{\sum(Y-\bar{Y})^{2}}{n-1}$ [eq. 4]

The variances of $\mathrm{x}$ and $\mathrm{y}$ measure the variability of the $\mathrm{x}$ scores and $\mathrm{y}$ scores around their respective sample means $(\bar{X}$ and $\bar{Y}$, considered separately).

\subsection{The Impact Matrix}

Based on the physical force concept, the paper proposes an assessment method to support policy-makers in making strategy decisions by combining results of the two techniques in an Impact Matrix. The Impact Matrix provides the relative positioning for aggregate impact on the vertical axis based on decomposition results, and the relative positioning for the direction of the impact on the horizontal axis based on correlation results. The higher its placement on the vertical axis, the greater the impact the process has on the perception of value.

The impact on renewable energy growth is defined as the rate of increase of the vector, which is the combination of aggregate impact and direction impact (cf. Figure 2). This means that the force, which produces acceleration for renewable energy growth in a given direction, has two components connected by a definite relation. One is the aggregate impact that pulls the renewable energy according to its scale; the other impacts give direction for the growth.

In general, decomposition results uncover the tension of different factors in enhancing renewable energy development. The struggle between the influencing factors results in renewable energy increase or decrease. Therefore, to promote renewable energy development, it is necessary to affect the whole market with the right impact factor at the right time.

To illustrate, renewable energy consumption increases linearly, when population increases, and economic growth results in more 
demand. This effect is described by the $\mathrm{X}$-axis. However, if there is no movement in the Y direction, there would be no acceleration for renewable energy development. It indicates that renewable energy share in TPES would decrease. When governments encourage renewable energy development, they push in the vertical direction, which therefore pulls renewable energy growth faster.

To determine the order of impacts on the renewable energy growth rate from strongest to weakest, we propose dividing the matrix into four parts (seen Figure 2):

- Zone I - major policy focus area, where the decomposition result ( $\Delta \mathrm{Ei})$ and the correlation result (r) have positive values.

- Zone II - potential focus area, where the decomposition result ( $\Delta \mathrm{Ei})$ is negative, but the correlation result (r) is positive.

- Zone III - no focus area, where both the decomposition result ( $\Delta \mathrm{Ei})$ and the correlation result (r) are negative.

- Zone IV - careful focus area, where the decomposition result $(\Delta \mathrm{Ei})$ is positive, but the correlation result (r) is negative.

\section{Figure 2. about here}

Zone I, with positive interaction and positive correlation, illustrates the strongest impact. Consequently, if policy-makers would focus on this area, it could accelerate renewable energy growth rate the most. We called Zone I the Major Policy Focus area.

Zone II, with positive correlation but negative interaction, covers the impacts that have naturally positive correlation with renewable energy growth rate, however, have insignificant motivation to promote faster growth. This part is called the Potential Focus area, which means if policy-makers focus on the influence elements in Zone II, they could move from insignificant impacts to a greater impact in Zone I.

Zone III includes all the factors that have plainly negative impact on renewable energy growth. It is called the No Focus area. Note that, no focus indicates that it is not a favorable focus to accelerate renewable energy increase for policy-makers.

Zone IV covers the factors that have a negative correlation with renewable energy growth rate, however, still shows its positive interaction. If the considered factors are placed in this area, policy-makers should be careful in creating more renewable energy supporting schemes, because it does not ensure a positive effect. This zone is called the Careful Focus area.

The most efficient option for policy makers to accelerate a renewable energy development is to keep the driving factor moving along the dissection of the the major policy focus quadrant, as can be seen in Figure 2 as the orientating reference.

\subsection{Collecting and sorting data}

In previous papers, researchers collected historical data at aggregate or country levels. This paper consecutively collects all these data as well as sector level for the period between 1995 and 2013 (see Table 5). It therefore approaches diverse perspectives of comparing different effects on renewable energy extension in ASEAN. However, since data collection is still lacking in ASEAN, only seven of ten countries are considered. However, since renewable energy in Brunei Darussalam is recorded with almost no development, all the results are shown in this study consisting only the other six countries.

With the purpose of focusing on understanding how the factors interact on renewable energy changes at the multi-level, this paper uses divergent data for renewable energy types. It means energy data is divided by sectors (end-used customers) and energy types (solar, wind, hydro, etc.). To ensure data reliability, we collected and adjusted data by comparing it from different sources (as seen in Table 5). It prevents errors in the first place since data is crucial in the calculation. For instance, renewable energy data is combined from IEA 2017 (IEA 2017) data source and IRENA Statistics 2017 source. While IEA 2017 provides an entire picture of the energy balance in the countries, IRENA Statistics 2017 focuses on renewable energy in general and particular types of it. However, there is a slight difference between this data, around $10 \%$ on average. Especially in case of individual renewable energy types, we used IRENA statistics 2017 after collating it with national reports.

Table 5. about here

\section{Results and discussion}

The results explain the trend of increasing renewable energy usage in the region by revealing the interdependency between renewable energy growth and other impact factors such as economic growth, urbanization growth, economic structure change and energy intensity change in the considered period from 1995 to 2013.

\subsection{Decomposition results}


We obtained the first results with the decomposition method from three different levels: the regional level (considering ASEAN as a whole), the country level and the sector level.

The regional level results reveal that renewable energy growth in ASEAN, as a whole (see Figure 3), is mostly driven by $\Delta E_{a c t}$ and $\Delta E_{u r}$, economic growth and urbanization growth (urban population growth) respectively. Compared to the two effects, the structure effect $\Delta E_{\text {str }}$ is relatively small. The energy transition effect $\left(\Delta E_{\text {mix }}\right)$ and especially the energy efficiency effect $\left(\Delta E_{\text {int }}\right)$ delay renewable energy growth.

Figure 3. about here

By separating these effects into country perspectives (see Fehler! Verweisquelle konnte nicht gefunden werden. for all effects and Fehler! Verweisquelle konnte nicht gefunden werden. for detailed economic growth and urbanization growth effects), the effects of economic growth and urbanization growth maintain their positive influence in all countries while other effects such as structure and energy mix effects show their positive or negative influence depending on the individual country. The economic growth and urbanization growth effects contribute estimated significant increases of renewable energy growth in all ASEAN countries. In contrast, the energy intensity effect is the main negative effect among the five considered effects on renewable energy growth. (see Fehler! Verweisquelle konnte nicht gefunden werden.)

Figure 4. about here

Looking at the two significant positive effects, the economic growth effect $\left(\Delta E_{\text {act }}\right)$ is more than twice as strong as the urbanization effect $\Delta E_{u r}$ in most of the countries, except for Malaysia and Thailand. In Malaysia, urbanization is almost as important as economic growth in motivating renewable energy. While in Thailand, it is indeed the most important factor, at roughly $10 \%$ stronger than the economic effect (detailed in Fehler! Verweisquelle konnte nicht gefunden werden.).

Figure 5. about here

Meanwhile the structure effect $-\Delta E_{\text {str }}$ is recorded positively in Thailand and Myanmar with a calculated increasing effect of about 153 and 28 thousand TOE respectively. The structure effect not only recorded an inhibitory effect on renewable energy growth in other countries, but also a positive effect followed by a negative effect during the considered period. Given all ASEAN economies bias towards industrialization, especially after 2000, it could increase energy consumption in these countries. Unfortunately, with mostly limited finance conditions in the region such as in Cambodia, the Philippines and Vietnam, it enhances fossil fuel consumption instead of renewables in these countries.

In contrast, the energy intensity effect $-\Delta E_{\text {int }}$, which reflects the efficiency of energy utilization, and improvement in energy efficiency, does not create renewable energy demand in any country. It has a dramatically negative impact of about 400 thousand TOE of renewable energy consumption in the Philippines, and about 342 thousand TOE in Thailand, corresponding to reductions of $163 \%$ and $74 \%$ of the renewable energy growth rate respectively. Hence, the energy intensity effect is the main force tending to decrease the renewable energy development.

The energy mix effect - $\Delta E_{\text {mix }}$ represents the energy transition process, by describing the structural change in the energy system. The positive calculated value of $\Delta E_{\text {mix }}$ is observed only in Thailand, encouraging a $41 \%$ renewable energy increase over the studied time period. In general, the energy transition is more effective in Thailand than revealed by the results in the other countries.

As mentioned, one of the paper's objectives is conducting comparative analysis in country and sector levels. Thus, to explore profoundly the factors influencing the extension of renewable-energy, we employ a multi-sector analysis using the data of the same period. However, instead of using aggregate data, we use the sectorial data that has some distinctness between different sectors including electricity, industrial, residential and transportation. For instance, in case of electricity, energy intensity is energy efficiency in electricity generation, thus, it is the fraction of total energy use for this purpose per total electricity generation and there is no economic structure effect for this sector. Alternatively, in residential case, we acknowledge the effect of household expenditure - GDP ratio instead of Value-added - GDP ratio as the industrial and transportation cases.

Detailed results are presented in Figure 6. The majority of the calculated cases show similar results in a region-level and countrylevel analysis, which determined a strong effect from economic growth $\Delta E_{\text {act }}$ with estimated pulling renewable energy increase of more than 100 thousand TOE in electricity and industrial sectors, and much greater in residential with more than 800 thousand TOE. This may suggest that economic growth as well as urbanization growth play relatively important roles in encouraging renewable energy. 
The feature, however, is different in the case of transportation, where the energy transition effect $\left(\Delta E_{\text {mix }}\right)$ overtakes the economic growth effect as the most significant force in driving renewable energy increases. Estimated calculation shows it almost five times as stronger than the economic growth effect $\left(\Delta E_{a c t}\right)$ and almost eight times stronger than the urbanization effect $\left(\Delta E_{u r}\right)$.

\section{Figure 6. about here}

\subsection{Correlation analysis}

Before analyzing the relation between renewable energy and its effects, the study carries out a test for normality. The results show the individual time-series data does not deviate significantly from the normal distribution at $1 \%$ and $5 \%$ significance levels. It qualifies for correlation analysis that is conducted to detect the trend of renewable energy growth following the trend of other factors.

The results in Table 6 illustrate the correlation analysis between renewable energy growths with their influence factors at $1 \%$ and $5 \%$ significance levels. In ASEAN, obviously, energy transition $\left(\Delta E_{\text {mix }}\right)$ has the strongest relationship with renewable energy growth. The faster the energy transition process, the more renewable energy development. Following this, it is the economic growth effect and the urbanization effect, $\Delta E_{a c t}$ and $\Delta E_{u r}$ respectively. In contrast, economic structure $\Delta E_{s t r}$ changes and energy efficiency $\Delta E_{\text {int }}$ improvements have negative correlations with renewable energy growth, with $r_{s t r}=-0.07$ stronger than $r_{\text {int }}=-$ 0.04 .

To investigate the correlation between renewable energy growth and its influencing factors, tests for correlation and cross-country comparisons are conducted. The presence of correlation between renewable energy and energy transition $\left(\Delta E_{\text {mix }}\right)$ is strongest with $\boldsymbol{r}_{\boldsymbol{m i x}}$ ranging from about 0.68 to 0.96 , correlation is significant at the 0.05 level (2-tailed). It means renewable energy growth depends significantly on the energy transition progress in all analysed countries.

The urbanization effect $\left(\Delta E_{u r}\right)$ demonstrates the second strongest effect on renewable energy extension at the $1 \%$ significance level, except for Malaysia. Positive signs of economic growth effect $\left(\Delta E_{a c t}\right)$ are shown in Myanmar, Thailand and Vietnam, in descending order respectively.

The correlation results of $\boldsymbol{r}_{\text {int }}$ show the dependence of renewable energy growth on the energy efficiency effect $\left(\Delta E_{\text {int }}\right)$. Apparently, $\boldsymbol{r}_{\boldsymbol{i n t}}$ is greater than zero in the case of Cambodia (0.59) and the Philippines (0.24), meaning energy efficiency improvement is proportional to a renewable energy increase. There is a need for more evidence to conclude about the special cases that will be conducted by the Impact Matrix in the following sub-section.

\section{Table 6. about here}

Table 7 shows the results of the correlation analysis at the sector level. There is evidence to conclude that the energy transition $\left(r_{\text {mix }}\right)$ correlates actively with renewable energy growth, especial in transportation with $r_{\text {mix }}=0.993$, and electricity with $r_{m i x}=0.881$. In other words, it could mean the energy transition has a more direct effect on renewable energy growth than the other factors, followed by the urbanization effect $\left(r_{u r}\right)$. The economic growth effect $\left(r_{a c t}\right)$ only shows an active effect on the industrial sector, but relatively weak. The energy intensity effect $\left(r_{\text {int }}\right)$, structure effect $\left(r_{s t r}\right)$ in industrial and transportation sectors, and expenditure effect in the residential case $\left(r_{\text {exp }}\right)$, all present relatively limited correlations with renewable energy growth.

Table 7. about here

\subsection{Impact Matrix analysis}

As discussed above, to overcome deficiencies of individual analyses, the Impact Matrix combines the results and reveals sufficient and convincing evidence about which factor is driving renewable energy development. At all three analysis levels including regional (see Figure 7), country (see Figure 8Figure 8) and sectoral (see Figure 9Figure 9) levels, there are similar findings.

Zone I: Major policy focus

Overall, economic growth ( $\Delta$ Eact) and urbanization ( $\Delta$ Eur) are the two factors placed in the major policy focus, in which economic growth $(\Delta$ Eact) has a much higher position than urbanization $(\Delta$ Eur), but on the left side. It means that despite the strong correlation between urbanization ( $\Delta$ Eur) and renewable energy growth, economic growth ( $\Delta$ Eact) is the main pull factor for renewable energy market development.

Figure 7. about here

By country, the economic growth generates the strongest promotion for renewable energy in Vietnam, followed by urbanization (Figure 8), while urbanization is the best motivator for Thailand, the Philippines, and Malaysia. However, the motivation of urbanization in Myanmar seems to be very low due to their place almost on the horizontal axis. 
By sector, the development in the power sector is most strongly affected by the economic factor, while demography as urbanization affects the most on renewable energy development in the residential sector (Figure 9). However, these two factors do not show a significant effect on transportation.

Figure 8. about here

Zone II: Potential policy focus

Energy transition $(\Delta$ Emix) is normally placed in the potential policy focus zone of the three analysis results, but much closer to the $\mathrm{X}$-axis than the $\mathrm{Y}$-axis. It shows that renewable energy increase depends strongly on the energy transition progress. However, the rate of the transformation process is slow.

Looking at the country analysis, we see a bright spot for the energy transition in Thailand. Moreover, looking at the sector level, we recognize $\Delta$ Emix located in the major focus area. Energy restructuring in Thailand and energy transition policy for transportation could be considered as best practice cases for other countries to follow.

Zone III: No focus

The energy efficiency effect $(\Delta$ Eint) commonly falls into the no focus area since there exists theoretically a negative relationship between the two variables. This is related to the fact that because of energy efficiency improvement, consumers demand less energy for the same condition, therefore they are not motivated to invest in alternative energy such as renewable energy.

Zone IV: Careful focus

The impact of economic structure $\Delta$ Estr appears in all four quarters of the Impact Matrix. However, it usually can be seen in the corner of careful focus. This argues that promoting industrialization does not necessarily have a positive impact on renewable energy development.

For example, there is a special appearance of the economic structure $\Delta$ Estr factor of Myanmar in the major focus area. To discover the reason for that, we have inspected the cause from the dataset of all countries and recognized a distinguished trend in Myanmar's economy. Compared with other countries, the industry share in total GDP in Myanmar decreased from 78\% in the beginning of considered period (1995) to around $60 \%$ in the last considered year 2013, while other countries recorded an increasing share of industry in total GDP. In addition, the economic structure $\Delta$ Estr factor can be noticed in the potential area for the cases of the Philippines and Vietnam, where the industry share increases at a slower pace.

Figure 9. about here

\subsection{Critical discussion of the method}

By dividing impact factors according to their strength and direction to certain priority level, the presented method represents a combination of two quantitative approaches. Starting with the decomposition approach, the method aims to calculate numeric values that describe the association of each factor with renewable energy change. Thereafter, a correlational analysis is conducted on variables to measure and demonstrate the presence of relationship between the impact factors and renewable energy growth. Combining two quantitative results, the impact matrix makes relative judgments in order to categorize the importance of the impact such as focus, potential, no focus and careful. The weight-scaled impact score is the combination of the correlation score and decomposition score. Therefore, it is able to compare different alternatives.

The Impact Matrix is developed to help determine how different factors affect renewable energy development. Therefore, it could support policy-makers to decide where to focus attention and reduce the problem of transparency between policy formulation and impacts. Due to this ability of cross comparing between region-country-sector-city, it could help to better understand the complex interactions between renewable energy development and the effects of energy transition, economic structure change, economic growth, and demographic change. It could therefore be useful in generating and analyzing scenarios in by using historical data combined with future projections.

Despite the usefulness of the Impact Matrix, it has some weaknesses. Firstly, it is unsuitable for application to prediction, but can assess the efficiency of the prediction according to defined objectives. Secondly, the Impact Matrix must be applied after certain time ex post, in order to control for the efficiency of the energy policy. For example, urban population changes cause economic and energy demand changes, but the impacts have a non-linear relationships and due to many simultaneous impacts on renewable energy, there is the possibility of a time delay in their realization. Thirdly, the Impact Matrix shows the interactions between each impact factors with renewable energy change. However, it is difficult to understand the interactions between the factors themselves. In the case of one impact propagating from one component to another, it is not necessarily linked directly to the other impacts. Furthermore, the Impact Matrix is not allow to depict the interconnection in a causal style between the impact factors. So it is difficult to conclude which impact factor causes other impact factor changes. Fourthly, the Impact Matrix only 
considers relative changes in effects through decomposition and correlation between the start and end of the period studied. It therefore overlooks changes in these effects between these points in time. Hence the developed method with the Impact Matrix should be extended in the context of further work and employed to analyze the potential impact of current and future renewable energy policies, by comparing the situation before and after (e.g. using scenarios) the policy implementation.

\section{Policy recommendations}

Because of the similarity at different levels, the results reveal a good argument for matching multi-level policy. Renewable energy programmes could be merged between regional, country and local levels. The European Union (EU) provides the obvious example for this type of harmonization. In the EU, regional targets at the European level for RE shares are broken down to and agreed with member states, according to the potentials for specific RE technologies and progress to date. Progress towards these national targets is achieved based on national and local policy instruments, a model that could also be applied in ASEAN. By doing so, ASEAN countries could save national and local resources in preparing and implementing renewable energy policy. From the results in section 4, we propose using economic growth and urbanization as two of the main criteria to select the target audience and use the Impact Matrix as one of the tools to review and revise policy.

As discussed in section 4, since they are the main drivers of renewable energy development, urban areas are crucial in the process of promoting renewable energy. Indeed, rural areas include masses of low-income people, who could mostly not afford the extra cost of decentralized renewable energy investment such as solar PV. On the other hand, urban areas concentrate high- and middleincome groups of people, who are more likely to be capable of investing. Secondly, energy consumption is mostly concentrated in urban areas with $75 \%$ of total energy consumption, compared to only $25 \%$ in rural areas (EIA 2017). Low demand in rural areas, consequently, would create much less motivation to use renewable energy compared to urban area. Lastly, rural areas have a much lower density than urban area, which would require more investment in energy system transmission and distribution infrastructure. Hence, it seems advantageous to concentrate future policy and governance measures on urban areas. Policy-makers should have more supporting schemes to promote public investment in decentralizing energy system instead of only focusing on supporting large investors.

At a national level, in general, the priority for urban areas and cities should be either as much as or even higher than rural areas in renewable energy policy. They should be one of the main target audiences for accelerating renewable energy growth. Some countries focusing on enhancing renewable energy consumption in rural areas such as Cambodia, Myanmar and Vietnam (Table 2) should consider adjusting their policy target groups. Countries without target groups such as Indonesia, Laos and the Philippines (Table 2) should consider establishing them because goals and objectives are a direction-setting base for renewable energy development. Besides the electricity sector, industrial and transportation sectors have three of four impact indicators in Zone I of the Impact Matrix (Figure 9). Therefore, policy makers should not only focus on the electricity sector but also need to support more non-electricity sectors.

Detailed recommendations for each country by sector are presented in Table 8. Each country could use this table as a suggestion in deciding whether the policy should stay at government or governance level. For example, looking at the results of electricity sector, it reveals that Cambodia need to focus in improving all the impact factors including energy transition, energy intensity, economic factor and urbanization factor. It would be too difficult for the governance to handle all of them alone without direct and strong supporting from government policy. Therefore, in this case, policy-makers should focus on improving their government policy.

Table 8. about here

The necessary conditions to improve renewable energy increase are economic growth and urbanization. The wealthier and more densely populated the area, the faster the renewable energy development stands to be. Thus, local policy makers should also focus on urban districts in accelerating renewable energy. Energy mix, which has strong relationship with renewable energy development but is still located in the potential zone, would be one of the sufficient conditions for renewable energy development in the area. By granting both necessary and sufficient conditions, renewable energy in the region would be ready to accelerate. To make the energy mix more strongly based on renewable energy development, policy makers should concentrate on improving planning for future grid extension and complete net-metering systems, for example.

Because the socio-economic situation in developing countries like ASEAN has changed at a rapid pace, policy makers at all levels should conduct the assessment after the specific period to adjust policy target audiences matching with the new situation. To assess the efficiency of the policy changes, the government and governance could compare the changes by assessing the differences between the current Impact Matrix and the previous Impact Matrix. If the influencing factors move from Zone III and IV to Zone II and I, the policy seems to work adequately. If the influencing factors in Zone II move in the direction of Zone I, and/or influencing factors in Zone I move from the 45 degree bottom corner to the 45 degree upper corner, the policy changes seem to work efficiently. 
Using the same methodology to set up target audiences and assess policy efficiency could enhance co-ordination between public authorities, donor agencies and project developers. Since policy makers, stakeholders and the public often have similar visions, it is better for them to reduce conflict potential and collaborate in planning. However, doing that requires the database synchronization at all levels that could be one of the first priorities for ASEAN to focus on in creating common strategies for cooperation to develop renewable energy in the region.

\section{Conclusion and outlook}

The ASEAN region has large potentials and favourable climatic conditions for renewable energies, but their exploitation is often hindered by geographical and technical conditions, inadequate regulatory frameworks, persistence of subsidies on conventional energy sources, import tariffs on renewable energy goods, and the lack of public awareness and support. ASEAN countries are taking important initial steps, but many opportunities remain for improving the overall renewable energy policy and regulatory environment. This paper provides evidence of the importance of governance policy, interaction by common target groups and combining action plans for policy-makers in establishing renewable energy policy.

By employing a correlation decomposition approach at regional, country and city levels, this paper investigates the determinants of renewable energy expansion and explores the trend drivers in ASEAN countries from 1995 to 2013. The results highlight the potential of economic growth associated with urban effects on renewable energy development, whilst at the same time ensuring rapid economic growth and urbanization. It confirms that urban areas should also be the focus of renewable energy policy in addition to rural areas. The tremendous impact of economic growth creates a great impetus for renewable energy development; urbanization ( $\Delta$ Eur) is the second pull for renewable energy extensions. Since the two effects are located in the first quadrant of the Impact Matrix, if strategists affect these factors, they will create the most powerful incentive for renewable energy growth. This confirms that if the strategic aim is to promote renewable energy market development, it is clear that the target must be focused on the richer and more crowded places. Due to the inverse effect of energy intensity, it supposes that the idea of integrating promotion policy for energy efficiency and renewable energy seems to be not a priority focus for renewable energy strategies. The energy transition should not only focus on electricity sector but also need more supporting mechanisms and schemes in nonelectricity sectors, especially in promoting the strategy of smart and green cities.

The overall target for renewable energy development in ASEAN seems ambitious if current policies are maintained. To achieve the 23 percent renewable target in 2025, each country within ASEAN needs to consider changing their individual policies. Having clear, well-defined goals and objectives is a critical first step in improving their policies. These could give a direction for setting strategies, plans and policies, whether they are used for regulation or governance at the national and/or local level. If a sector need high attention on all the impact factors, it is a clear message to the policy-maker to keep focusing on government policy and governance policy at national level.

The main problem in renewable energy policy in the region is the insufficient regulatory framework, lacking clear specific targets at the national level, and no target at a local level. The root cause seems to be that they do not have the tools to make decisions and select target audiences, with confusion in translating national objectives into local targets. Some countries are combining electrification with smart and green city targets in designing renewable energy policy. So local governments do not know what should be the first priority. The clear selection criteria and assessing policy matrix as proposed in this paper would provide a systematic approach to developing renewable energy policy at national and local levels. The criteria and the Impact matrix provide a common 'language' for urban government and governance in collaborating. They can be used to make policy more transparent and convincing to stakeholders by providing quantitative answers to questions of target setting in a specified period.

If Southeast Asian countries should redirect their renewable energy supporting schemes to make the urbanization trend environmentally sustainable, many actors need to work together to come up with solutions. For example, not only the government, but also businesses, citizens and governance processes should be involved. Economic growth in urban areas could encourage household investment in renewable energy, especially in solar PV. It also helps to tackle increasing energy consumption in the area. Therefore, renewable energy policy should create supporting mechanisms not only for the supply side but also for the demand side.

\section{Acknowledgements}

The Vietnamese Education Fellowship Program financially supported this research.

\section{Publication bibliography}


Gouldson, A.; Colenbrander, S.; Papargyropoulou, F. (2016): Policy Options for Low Carbon Cities Johor Bahru and Pasir Gudang, Malaysia.

Ang, B. W. (2005): The LMDI approach to decomposition analysis. A practical guide. In Energy Policy 33 (7), pp. 867-871. DOI: $10.1016 /$ j.enpol.2003.10.010.

Ang, B. W. (2006): Monitoring changes in economy-wide energy efficiency. From energy-GDP ratio to composite efficiency index. In Energy Policy 34 (5), pp. 574-582. DOI: 10.1016/j.enpol.2005.11.011.

Ang, B. W.; Huang, H. C.; Mu, A. R. (2009): Properties and linkages of some index decomposition analysis methods. In Energy Policy 37 (11), pp. 4624-4632. DOI: 10.1016/j.enpol.2009.06.017.

Ang, B. W.; Liu, F. L.; Chew, E. P. (2003): Perfect decomposition techniques in energy and environmental analysis. In Energy Policy 31 (14), pp. 1561-1566. DOI: 10.1016/S0301-4215(02)00206-9.

Ang, B. W.; Liu, F. L.; Chung, Hyun-Sik (2004): A generalized Fisher index approach to energy decomposition analysis. In Energy Economics 26 (5), pp. 757-763. DOI: 10.1016/j.eneco.2004.02.002.

Ang, B.W (2004): Decomposition analysis for policymaking in energy. In Energy Policy 32 (9), pp. 1131-1139. DOI: $10.1016 / \mathrm{S} 0301-4215(03) 00076-4$.

Rahmadi, A.; Hanifah, H.; Kuntjara, H. (2017): Renewable Energy in ASEAN: An Investment Guidebook. In The Habibie Center (ISBN: 978-979-1255-25-7).

ASEAN Centre for Energy (ACE) (2017): The 5th ASEAN Energy Outlook 2015-2040. In ASEAN Centre for Energy (ACE).

ASEAN Centre for Energy (ACE) (2018): Study on Regional Renewable Energy Cooperation in ASEAN. Strengthening Cooperation to Reach ASEAN Renewable Energy Target. In ASEAN Centre for Energy (ACE).

Asian Development Bank (2015): Renewable Energy Developments and Potential in the Greater Mekong Subregion. In Asian Development Bank (ISBN 978-92-9254-831-5 (Print), 978-92-9254-832-2 (e-ISBN)).

Boyd, G. A.; Roop, J. M. (2004): A Note on the Fisher Ideal Index Decomposition for Structural Change in Energy Intensity. In EJ 25 (1). DOI: 10.5547/ISSN0195-6574-EJ-Vol25-No1-5.

Chimres, N.; Wongwises, S. (2016): Critical review of the current status of solar energy in Thailand. In Renewable and Sustainable Energy Reviews 58, pp. 198-207. DOI: 10.1016/j.rser.2015.11.005.

Daniel M. K.; Deborah A. S. (2016): City-integrated renewable energy for urban sustainability. In Urban Planet - Special Section $352(6288)$.

Sirasoontorn, P.; Koomsup, P. (2017): Energy transition in Thailand. Challenges and Opportunities. In Friedrich-Ebert-Stiftung.

Tongsopit, S., at el (2015): Scaling Up Solar PV: A Roadmap for Thailand. In Energy Research Institute Chulalongkorn University.

Eskew, J.; Ratledge, M.; Wallace, M.; Gheewala, S. H.; Rakkwamsuk, P. (2018): An environmental Life Cycle Assessment of rooftop solar in Bangkok, Thailand. In Renewable Energy 123, pp. 781-792. DOI: 10.1016/j.renene.2018.02.045.

High-level Political Forum (2017): Malaysia SDG 2017 recommend for governance 2017. In Government of Malaysia.

Hoekstra, R.; Bergh, J.C.J.M. (2003): Comparing structural decomposition analysis and index. In Energy Economics 25 (1), pp. 39-64. DOI: 10.1016/S0140-9883(02)00059-2.

IEA - International Energy Agency (2017): WEO-2017 Special Report_Southeast Asia Outlook. In International Energy Agency. IMF - Internation Monetary Fund: World Economic Outlook, April 2018: Cyclical Upswing, Structural Change April 17, 2018. International Energy Agency (2010): Deploying Renewables in Southeast Asia. In International Energy Agency.

IRENA (2018): Renewable Energy Market Analysis: Southeast Asia. In International Renewable Energy Agency (ISBN 978-929260-056-3).

IRENA; ASEAN Centre for Energy (ACE) (2016): Renewable Energy Outlook for ASEAN: A REmap Analysis. In International Renewable Energy Agency (ISBN 978-92-95111-28-8).

Ishugah, T. F.; Li, Y.; Wang, R. Z.; Kiplagat, J. K. (2014): Advances in wind energy resource exploitation in urban environment. A review. In Renewable and Sustainable Energy Reviews 37, pp. 613-626. DOI: 10.1016/j.rser.2014.05.053.

Ismail, A.M.; Ramirez-Iniguez, R.; Asif, M.; Munir, A.B.; Muhammad-Sukki, F. (2015): Progress of solar photovoltaic in ASEAN countries. A review. In Renewable and Sustainable Energy Reviews 48, pp. 399-412. DOI: 10.1016/j.rser.2015.04.010. 
Karimu, A.; Brännlund, R.; Lundgren, T.; Söderholm, P. (2017): Energy intensity and convergence in Swedish industry. A combined econometric and decomposition analysis. In Energy Economics 62, pp. 347-356. DOI: 10.1016/j.eneco.2016.07.017.

Lin, C.; Chen, W.; Liu, S.; Liou, Y.; Liu, G.; Lin, T. (2008): Numerical study of the impact of urbanization on the precipitation over Taiwan. In Atmospheric Environment 42 (13), pp. 2934-2947. DOI: 10.1016/j.atmosenv.2007.12.054.

Liu, Y. (2009): Exploring the relationship between urbanization and energy consumption in China using ARDL (autoregressive distributed lag) and FDM (factor decomposition model). In Energy 34 (11), pp. 1846-1854. DOI: 10.1016/j.energy.2009.07.029.

Lee, M.: Sustainable Development Governance of the Energy Sector in Malaysia. In OIDA International Journal of Sustainable Development, Ontario International Development Agency, Canada (ISSN 1923-6654 (print) ISSN 1923-6662 (online)).

Marquardt, J. (2014): A Struggle of Multi-level Governance. Promoting Renewable Energy in Indonesia. In Energy Procedia 58, pp. 87-94. DOI: 10.1016/j.egypro.2014.10.413.

Nicholas A.; Dan, C. D.: Renewable Energy and Economic Growth: Evidence from the Sign of Panel Long-Run Causality 4 (SSN: 2146-4553), pp. 578-587.

OECD (2018): Economic Outlook for Southeast Asia, China and India 2018. Fostering growth through digitalisation. Paris: OECD Publishing (Economic outlook for Southeast Asia, China and India, 2018).

Saad, W.; Taleb, A. (2017): The causal relationship between renewable energy consumption and economic growth. Evidence from Europe. In Clean Techn Environ Policy 22 (5), p. 209. DOI: 10.1007/s10098-017-1463-5.

Sahar S.; Ruhul A. S.; Cabalu, H.: The Nexus between Energy Consumption and Economic Growth in OECD countries: A Decomposition Analysis.

Shakouri, B.; Khoshnevis Yazdi, S. (2017): Causality between renewable energy, energy consumption, and economic growth. In Energy Sources, Part B: Economics, Planning, and Policy 12 (9), pp. 838-845. DOI: 10.1080/15567249.2017.1312640.

Singh, R.; Banerjee, R. (2015): Estimation of rooftop solar photovoltaic potential of a city. In Solar Energy 115, pp. 589-602. DOI: 10.1016/j.solener.2015.03.016.

Heinen, S. (2013): Analyzing Energy Use with Decomposition Methods. Energy Technology Policy Division - IEA. Paris (Energy Training Week).

Terziotti, L. T.; Sweet, M. L.; McLeskey, J. T. (2012): Modeling seasonal solar thermal energy storage in a large urban residential building using TRNSYS 16. In Energy and Buildings 45, pp. 28-31. DOI: 10.1016/j.enbuild.2011.10.023.

The Economist Intelligence Unit (2016): ASEAN cities Stirring the melting pot.

Tongsopit, S. (2015): Thailand's feed-in tariff for residential rooftop solar PV systems. Progress so far. In Energy for Sustainable Development 29, pp. 127-134. DOI: 10.1016/j.esd.2015.10.012.

Wang, Q. (2014): Effects of urbanisation on energy consumption in China. In Energy Policy 65, pp. 332-339. DOI: 10.1016/j.enpol.2013.10.005

Wang, H.; Ang, B. W.; Su, Bin (2017): Assessing drivers of economy-wide energy use and emissions. IDA versus SDA. In Energy Policy 107, pp. 585-599. DOI: 10.1016/j.enpol.2017.05.034.

Wei, H.; Liu, J.; Yang, B. (2014): Cost-benefit comparison between Domestic Solar Water Heater (DSHW) and Building Integrated Photovoltaic (BIPV) systems for households in urban China. In Applied Energy 126, pp. 47-55. DOI: 10.1016/j.apenergy.2014.04.003.

Yang, J.; Zhang, W.; Zhang, Z. (2016): Impacts of urbanization on renewable energy consumption in China. In Journal of Cleaner Production 114, pp. 443-451. DOI: 10.1016/j.jclepro.2015.07.158.

Yatim, P.; Mamat, M.; Mohamad-Zailani, S. H.; Ramlee, S. (2016): Energy policy shifts towards sustainable energy future for Malaysia. In Clean Technology Environmental Policy 18 (6), pp. 1685-1695. DOI: 10.1007/s10098-016-1151-x.

Zhang, F.Q; Ang, B.W (2001): Methodological issues in cross-country/region decomposition of energy and environment indicators. In Energy Economics 23 (2), pp. 179-190. DOI: 10.1016/S0140-9883(00)00069-4.

Zhang, J.; Jiang, J. (2016): Decomposition-based tensor learning regression for improved classification of multimedia. In Journal of Visual Communication and Image Representation 41, pp. 260-271. DOI: 10.1016/j.jvcir.2016.10.006. 


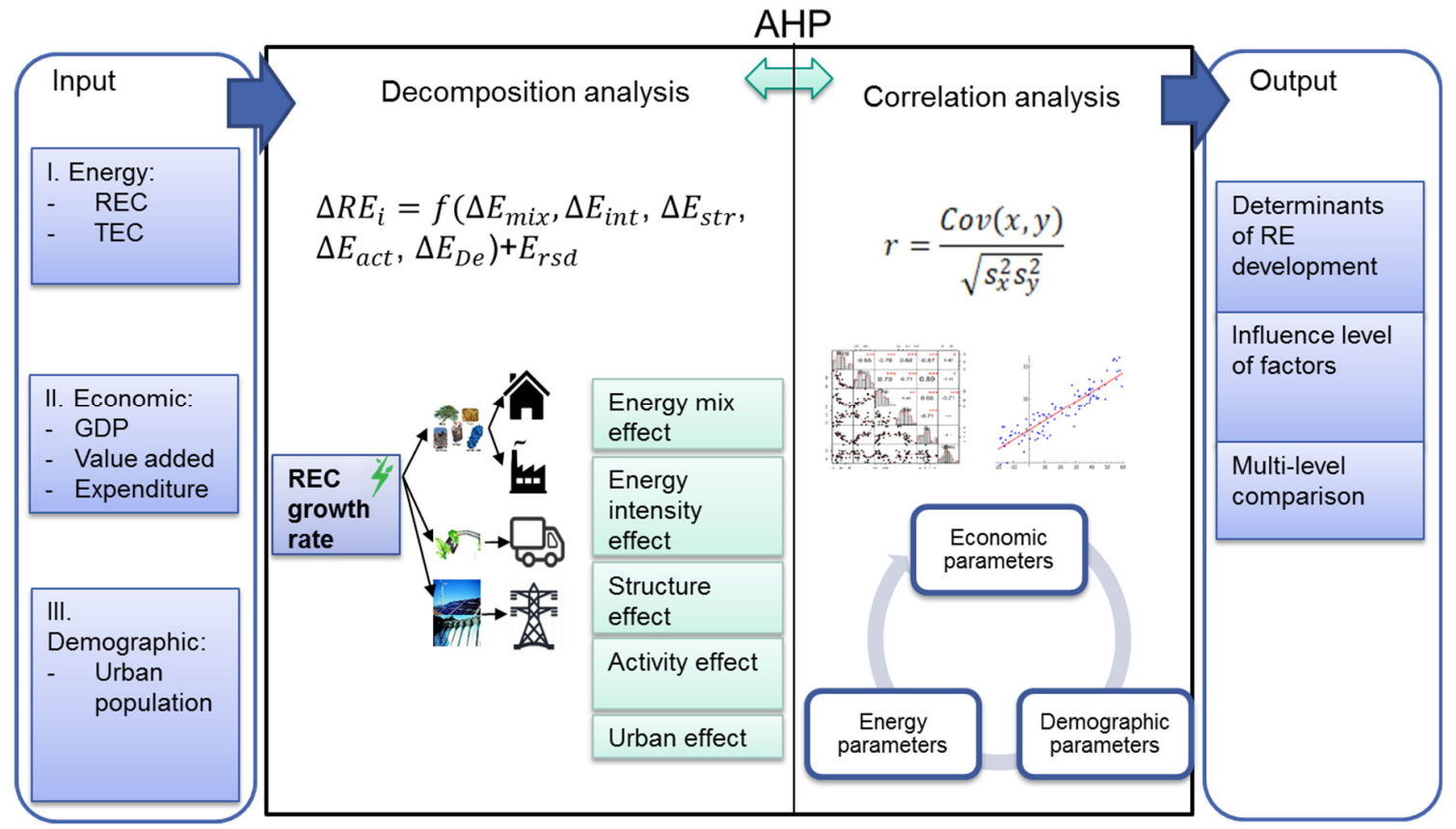

Figure 1. Model concept for quantitative analysis

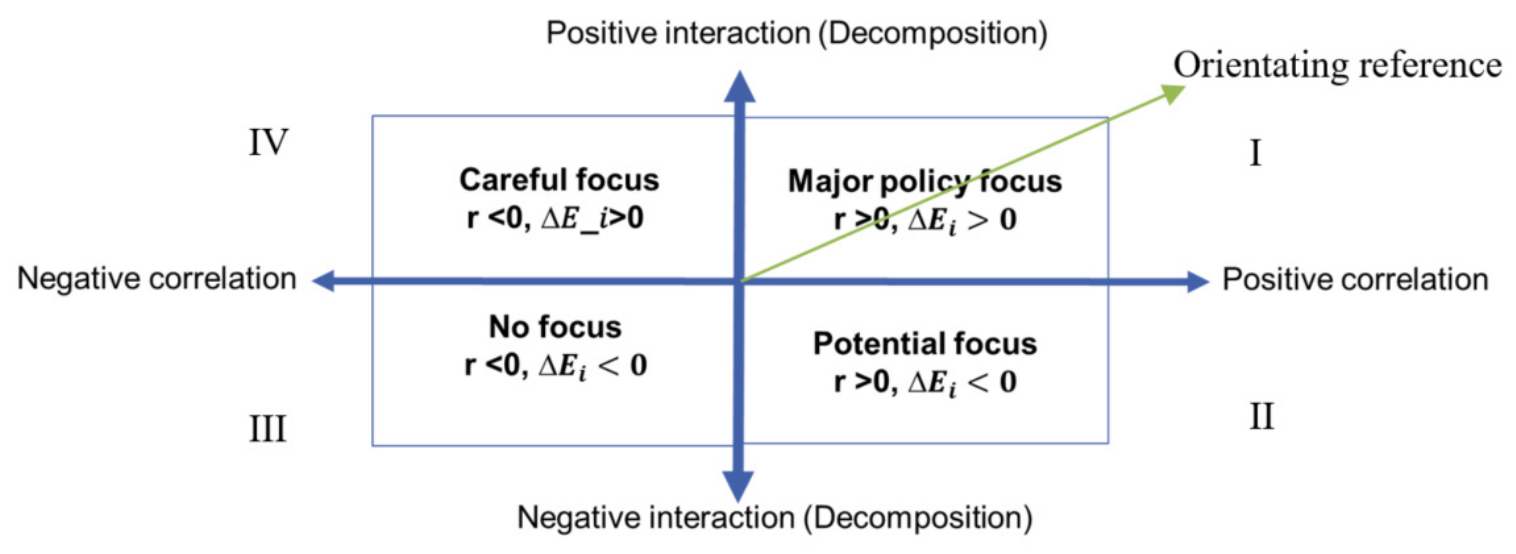

Figure 2. Proposed impact matrix to support policymaking

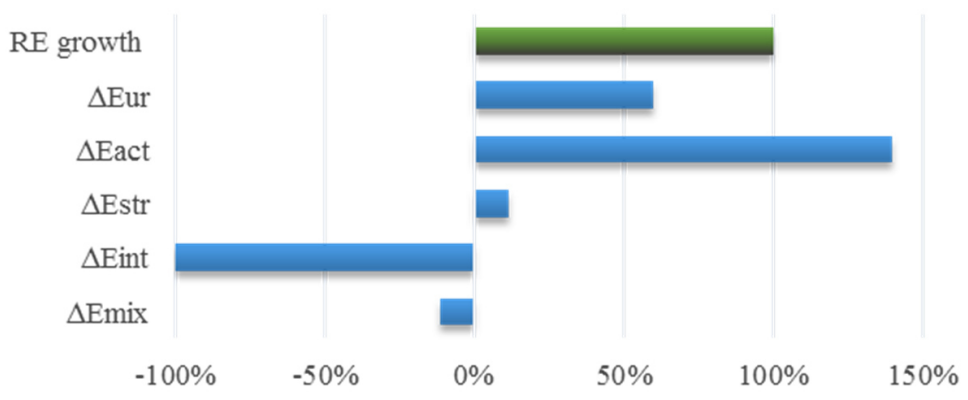


Figure 3. Cumulated effect of impact factors on renewable energy growth in 7/10 ASEAN countries from 1995 to 2013

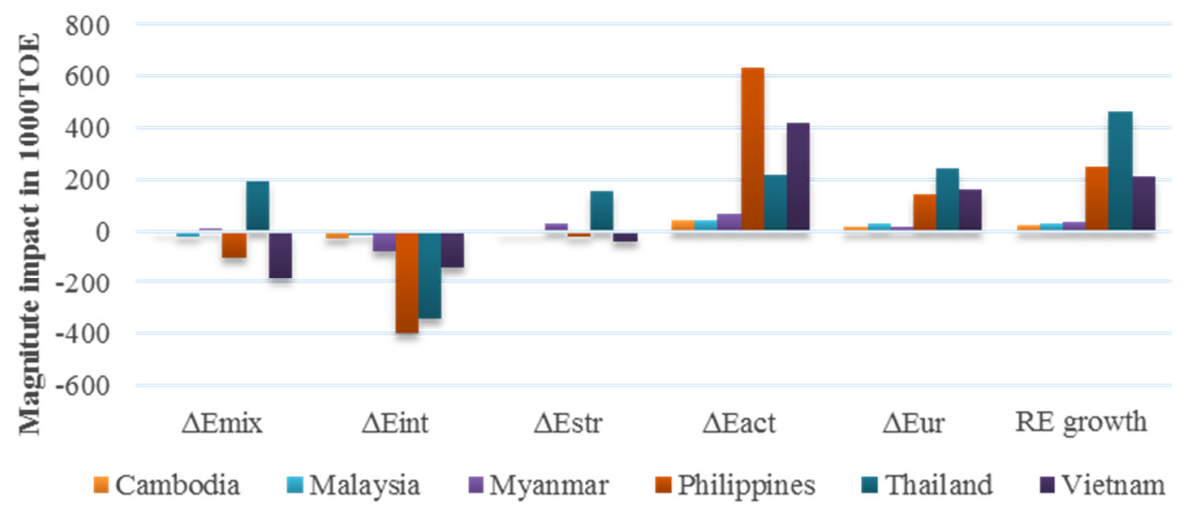

Figure 4. Dispersed effect of impact factors on renewable energy growth in ASEAN from 1995 to 2013

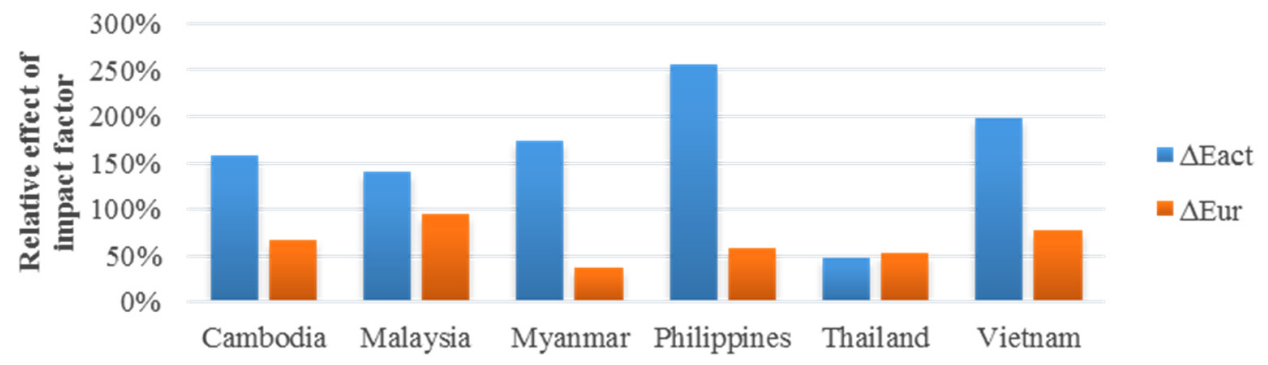

Figure 5. Decomposed effect of economic growth and urbanization on renewable energy growth by country in ASEAN from 1995 to 2013 

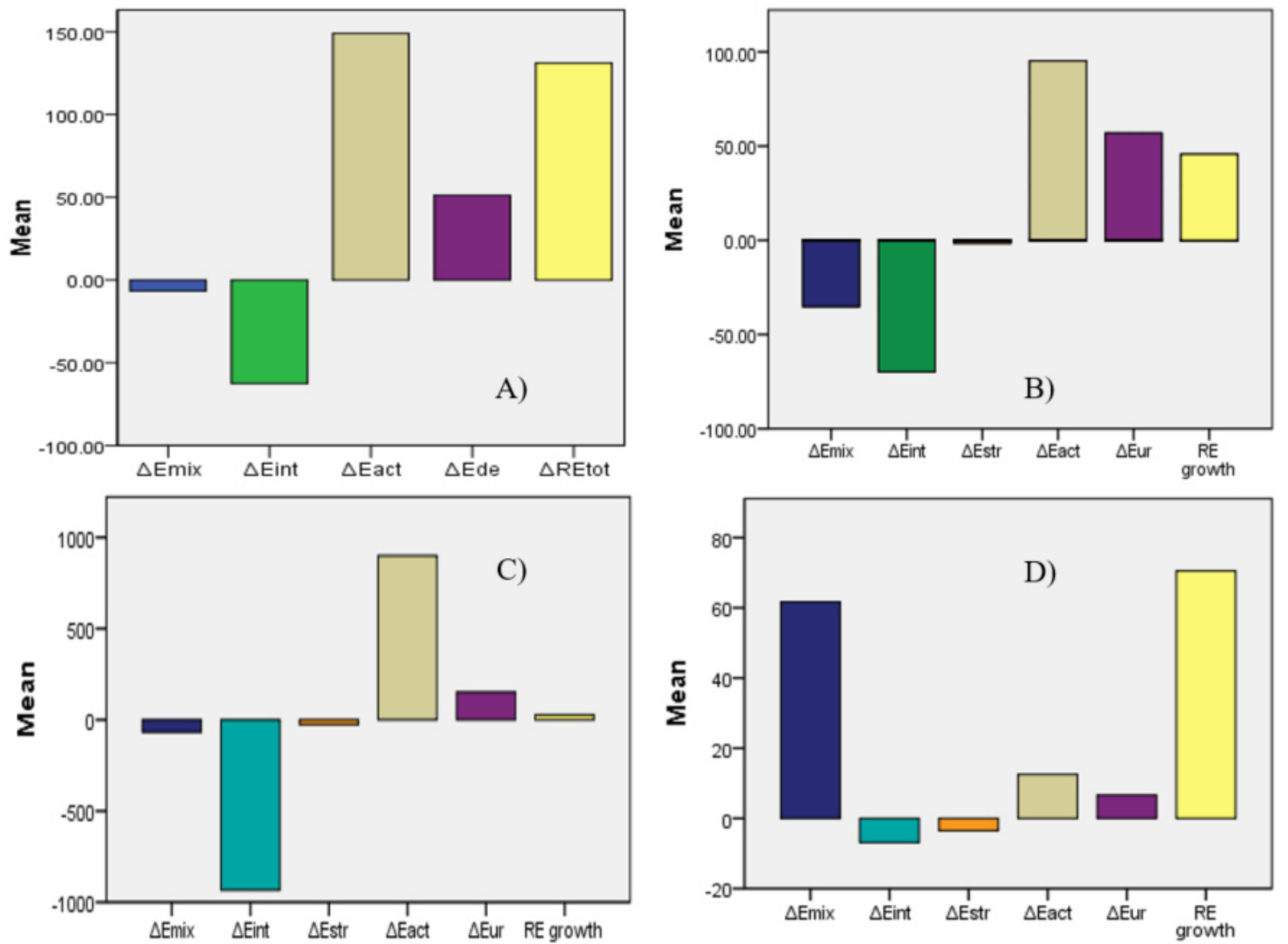

Figure 6. Decomposition analysis results. Mean of effects on a) electricity sector, b) industrial sector, c) residential sector, d) transportation sector in ASEAN countries by 1995-2013. Unit: 1000 toe.

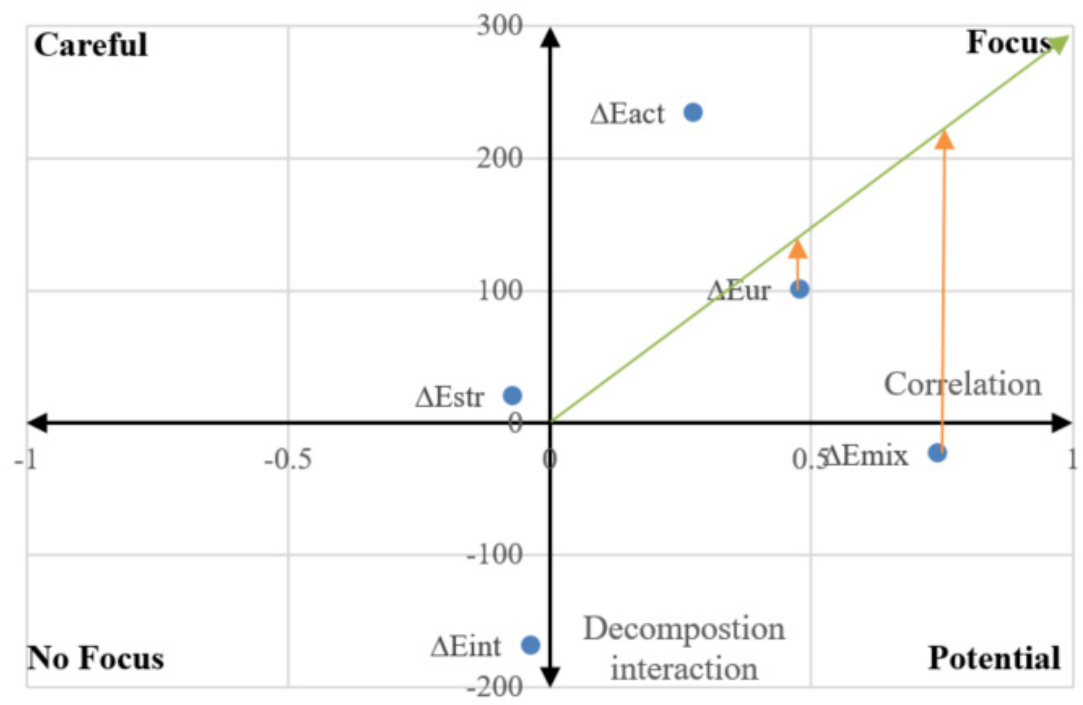

Figure 7. Impact matric analysis for ASEAN as a whole. Unit of y-axis: 1000 toe 


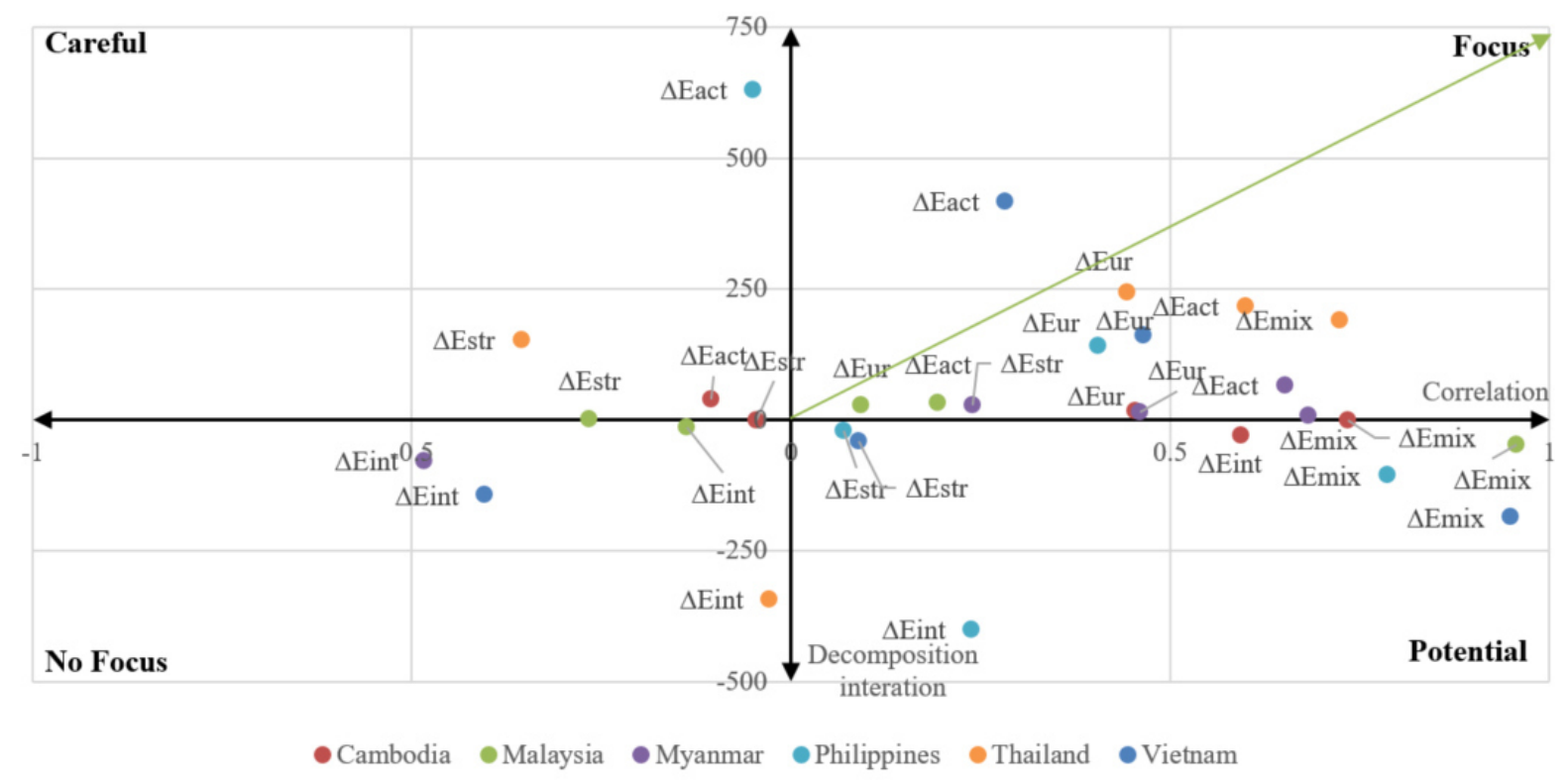

Figure 8. Impact matric analysis for ASEAN by countries. Unit of y-axis: 1000 toe

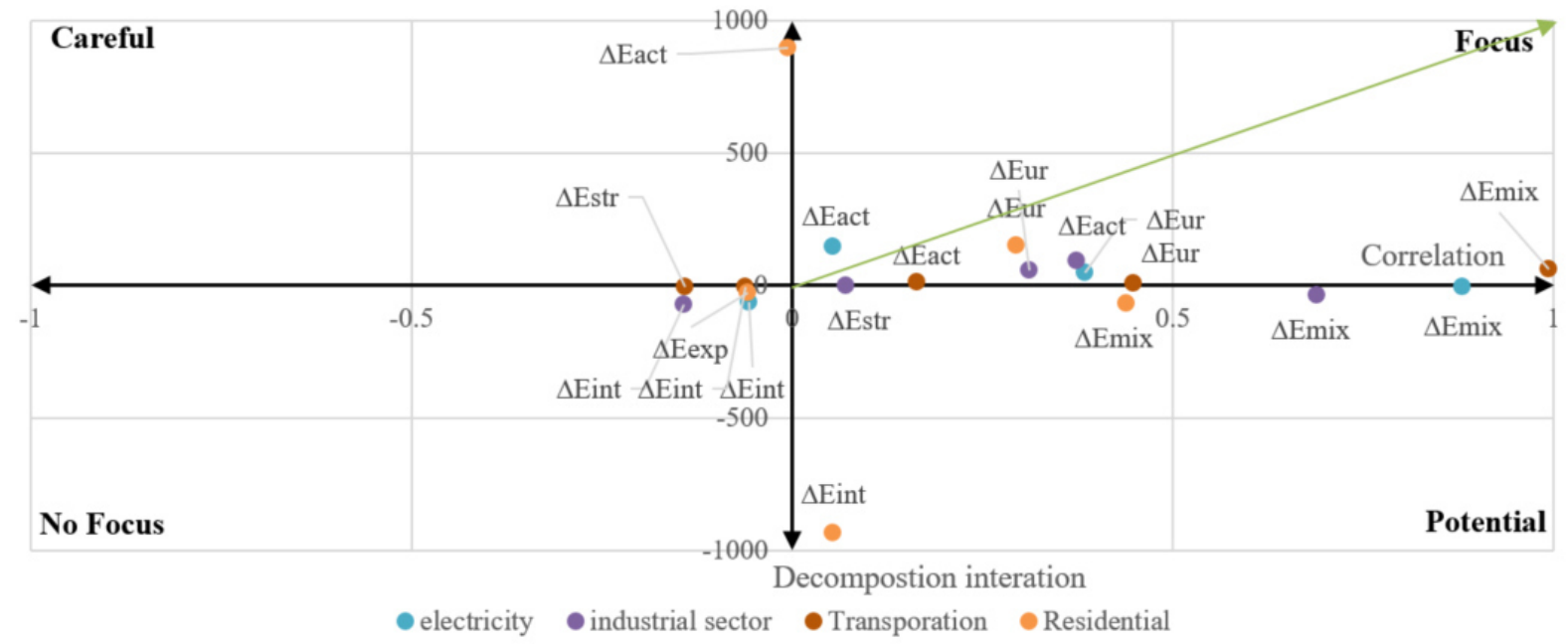

Figure 9. Impact matric analysis for ASEAN by sector. Unit of y-axis: 1000 toe 
Table 1.

Progress to renewable energy target of ASEAN countries in 2015

\begin{tabular}{|c|c|c|c|c|c|c|c|c|}
\hline & $\begin{array}{l}\text { Target } \\
\text { year }\end{array}$ & $\begin{array}{c}\text { Installed } \\
\text { capacity } \\
\text { target } \\
\text { (MW) }\end{array}$ & Specialization & $\begin{array}{c}\text { Installed } \\
\text { capacity } \\
2015 \\
(\mathrm{MW})\end{array}$ & $\begin{array}{c}\text { Progress } \\
\text { to target } \\
2015\end{array}$ & $\begin{array}{c}\text { Target } \\
\text { for } \\
\text { solar } \\
\text { (MW) }\end{array}$ & $\begin{array}{c}\text { Installed } \\
\text { solar } \\
2015 \\
\text { (MW) }\end{array}$ & $\begin{array}{c}\text { Progress } \\
\text { to target } \\
2015\end{array}$ \\
\hline $\begin{array}{l}\text { Brunei } \\
\text { Darsm }\end{array}$ & 2025 & $\begin{array}{c}954 \\
(\mathrm{GWh})\end{array}$ & All & $2 \mathrm{GWh}$ & $0.2 \%$ & - & 1 & - \\
\hline Cambodia & 2020 & 2241 & Hydro & 931 & $41.5 \%$ & - & 12 & - \\
\hline Indonesia & 2025 & 46307 & $\begin{array}{l}\text { Exclude } \\
\text { biomass }\end{array}$ & 6709 & $14.4 \%$ & 80 & 9 & $11.25 \%$ \\
\hline Lao PDR & 2025 & 951 & $\begin{array}{l}\text { Exclude large } \\
\text { hydro }\end{array}$ & 31 & $3.2 \%$ & 33 & 1 & $3 \%$ \\
\hline Malaysia & 2020 & 2080 & $\begin{array}{c}\text { Solar, } \\
\text { biomass, small } \\
\text { hydro }\end{array}$ & 1360 & $65.3 \%$ & 4200 & 262 & $6 \%$ \\
\hline Myanmar & 2030 & 2000 & Exclude hydro & 12 & $0.6 \%$ & - & 12 & - \\
\hline Philippines & 2030 & 15304 & $\begin{array}{l}\text { Geothermal, } \\
\text { hydro, wind }\end{array}$ & 6260 & $40 \%$ & 350 & 132 & $37.7 \%$ \\
\hline Singapore & 2020 & - & - & - & - & 350 & 60 & $17.1 \%$ \\
\hline Thailand & 2036 & 19684 & $\begin{array}{l}\text { Hydropower, } \\
\text { biomass, solar, } \\
\text { wind }\end{array}$ & 7432 & $37.7 \%$ & $2000 *$ & 1425 & $72.6 \%$ \\
\hline Vietnam & 2030 & 45800 & Total & 11956 & $26.1 \%$ & $6000 * *$ & $139 * *$ & $2.3 \%$ \\
\hline
\end{tabular}

Note: *: target for 2020. **: target and installed capacity for both wind and solar. Source: Renewable energy market analysis - Southeast Asia-IRENA 2018; IRENA statistic 2017; Pranadi, A. D. (2016), 'The Current Status of RE and Its Targets in ASEAN Member States', ASEAN Center for Energy Blog, 15th September, retrieved from: http://www. ASEANenergy.org/blog/the-current-statusof-re-and-its-target-in-ASEAN-memberstates/ 
Table 2.

Overview of renewable energy policy in ASEAN

\begin{tabular}{|c|c|c|c|c|c|c|c|c|}
\hline & \multicolumn{5}{|c|}{ Government policy } & \multirow{2}{*}{$\begin{array}{c}\text { R\&D } \\
2013 \\
\text { £Million }\end{array}$} & \multirow{2}{*}{$\begin{array}{c}\text { Investment } \\
\text { status }\end{array}$} & \multirow{2}{*}{$\begin{array}{c}\text { Integrated } \\
\text { Governance } \\
\text { Policy }\end{array}$} \\
\hline Country & $\begin{array}{c}\text { National } \\
\text { programme }\end{array}$ & FiT & $\begin{array}{l}\text { Subsidy } \\
\text { and } \\
\text { grants }\end{array}$ & $\begin{array}{c}\text { Tax } \\
\text { deduction }\end{array}$ & Specialization & & & \\
\hline $\begin{array}{l}\text { Brunei } \\
\text { Darsm }\end{array}$ & - & - & - & - & - & - & Insignificant & - \\
\hline Cambodia & - & - & $\mathrm{X}$ & - & $\begin{array}{l}\text { Own PV, } \\
\text { Rural, Off- } \\
\text { grid }\end{array}$ & - & Insignificant & - \\
\hline Indonesia & $\mathrm{X}$ & $X$ & - & $\mathrm{X}$ & - & - & Increasing & - \\
\hline Lao PDR & $\mathrm{X}$ & - & $\mathrm{X}$ & - & Small hydro & - & Insignificant & - \\
\hline Malaysia & $\mathrm{X}$ & $\mathrm{X}$ & - & $X$ & $\begin{array}{c}\text { Solar, No } \\
\text { wind }\end{array}$ & 28.3 & Increasing & $X^{*}$ \\
\hline Myanmar & - & - & $X$ & - & $\begin{array}{c}\text { Off-grid, } \\
\text { Rural }\end{array}$ & - & Insignificant & - \\
\hline Philippines & $X$ & $X$ & $\mathrm{X}$ & $X$ & - & $\begin{array}{c}64.5 \\
\text { (ADB) }\end{array}$ & Decreasing & - \\
\hline Singapore & $\mathrm{X}$ & - & $\mathrm{X}$ & - & Only solar & 329 & Increasing & - \\
\hline Thailand & $X$ & $\mathrm{X}$ & $\mathrm{X}$ & - & $\begin{array}{l}\text { Bioenergy, } \\
\text { Solar heating }\end{array}$ & 120 & Increasing & $\mathrm{X}$ \\
\hline Vietnam & $\mathrm{X}$ & $\mathrm{X}$ & $\mathrm{X}$ & $\mathrm{X}$ & Rural & - & Decreasing & - \\
\hline
\end{tabular}

Note: *. The policy is being preparing for implementation. Source: ASEAN Plan of Action for Energy Ccoopération (APAEC) 2016-2025. Abdul Muhaimin Ismail, Roberto Ramirez-Iniguez, Muhammad Asif, Abu Bakar Munir,

Firdaus Muhammad-Sukki, progress of solar photovoltaic in ASEAN countries: A review. Renewable and Sustainable Energy Reviews 48 (2015) 399-412. http://dx.doi.org/10.1016/j.rser.2015.04.010, Renewable energy market analysis - Southeast asia - IRENA 2018 
Table 3.

Category for symbol

\begin{tabular}{cccc}
\hline \hline Symbol & Name & Symbol & Name \\
\hline$R E$ & Renewable energy type i & $P G$ & Generated power \\
$E$ & Total energy consumption & $\mathrm{r}$ & Residential consumption \\
$V A j$ & Value added sector $\mathrm{j}$ & $\mathrm{tr}$ & Transportation sector \\
$G D P$ & Gross domestic production & $e l$ & Power generation sector \\
$E X P$ & Expenditure on GDP & in & Industrial sector \\
$U r$ & Urban population & & \\
\hline \hline
\end{tabular}

Table 4.

Category for indicators and their meaning

\begin{tabular}{|c|c|c|c|}
\hline Symbol & Effect & Calculation & Meaning \\
\hline$\Delta E_{m i x}$ & $\begin{array}{c}\text { Energy mix } \\
\text { effect }\end{array}$ & $\begin{array}{l}\text { Change of renewable energy share in } \\
\text { total energy supply }\end{array}$ & Energy transition performance \\
\hline$\Delta E_{\text {int }}$ & Intensity effect & $\begin{array}{l}\text { Units of energy consumption per unit of } \\
\text { added-value }\end{array}$ & Energy efficiency changes \\
\hline$\Delta E_{s t r}$ & Structure effect & Sector's unit profit share in GDP & $\begin{array}{c}\text { Economic bias: industrialization or } \\
\text { commercialization }\end{array}$ \\
\hline$\Delta E_{a c t}$ & Activity effect & GDP unit per demographic unit & Economic growth \\
\hline$\Delta E_{u r}$ & $\begin{array}{l}\text { Demographic } \\
\text { effect }\end{array}$ & Urban population in urban areas & Market size growth \\
\hline
\end{tabular}

Table 5.

Category for data and its illustration symbols

\begin{tabular}{cccc}
\hline \hline Symbol & Illustration & Unit & Sources \\
\hline$R E i$ & Renewable energy consumption in & 1000 TOE & IEA 2017, IRENA Statistics 2017 \\
$E i$ & Eector i & & IEA 2017 \\
$V A j$ & Value-added of sector I at 2000 market & Millions US \$ & Adjusted from World bank 2018
\end{tabular}




\begin{tabular}{|c|c|c|c|}
\hline$G D P$ & $\begin{array}{c}\text { Gross Domestic Production at } 2000 \\
\text { market prices }\end{array}$ & Millions US \$ & World bank 2018, ADB 2015 \\
\hline$U r$ & Urban population & people & World bank 2018 \\
\hline$E x$ & $\begin{array}{c}\text { Expenditure on GDP at } 2000 \text { market } \\
\text { prices }\end{array}$ & Millions US \$ & $\begin{array}{c}\text { Adjusted from ADB } 2015 \& \\
\text { World bank } 2018\end{array}$ \\
\hline
\end{tabular}

Note: Data lacking: Laos, Indonesia, Singapore

Table 6. Correlation between impact effects with renewable energy growth in whole ASEAN and countries over period 1995-2013

\begin{tabular}{|c|l|l|l|l|l|l|l|}
\hline & ASEAN & Cambodia & Malaysia & Myanmar & Philippines & Thailand & Vietnam \\
\hline$\Delta \boldsymbol{r}_{\boldsymbol{m i x}}$ & $0.74^{* *}$ & $0.73^{* *}$ & $0.96^{* *}$ & $0.68^{* *}$ & $0.79 * *$ & $0.72^{* *}$ & $0.95^{* *}$ \\
\hline$\Delta \boldsymbol{r}_{\boldsymbol{i n t}}$ & -0.04 & $0.59^{* *}$ & -0.14 & $-0.48^{*}$ & 0.24 & -0.03 & -0.40 \\
\hline$\Delta \boldsymbol{r}_{\boldsymbol{s t r}}$ & -0.07 & -0.04 & -0.27 & 0.24 & 0.07 & -0.36 & 0.09 \\
\hline$\Delta \boldsymbol{r}_{\boldsymbol{a c t}}$ & $0.28^{* *}$ & -0.10 & 0.19 & $0.65^{* *}$ & -0.05 & $0.60^{* *}$ & 0.28 \\
\hline$\Delta \boldsymbol{r}_{\boldsymbol{u r}}$ & $0.48^{* *}$ & $0.45^{*}$ & 0.09 & $0.46^{*}$ & $0.40^{*}$ & $0.44^{*}$ & $0.46^{*}$ \\
\hline
\end{tabular}

Note: ** Correlation is significant at the 0.01 level (2-tailed). * Correlation is significant at the 0.05 level (2-tailed).

Table 7. Correlation between impact effects with renewable energy growth by sector in ASEAN over period 1995-2013

\begin{tabular}{|l|l|l|l|l|}
\hline & Electricity & Industrial & Residential & Transportation \\
\hline$\Delta \boldsymbol{E}_{\boldsymbol{m i x}}$ & $.881^{* *}$ & $.698^{* *}$ & $.439 * *$ & $.993 * *$ \\
\hline$\Delta \boldsymbol{E}_{\text {int }}$ & -.057 & -.143 & .054 & -.061 \\
\hline$\Delta \boldsymbol{E}_{\text {str }}$ & - & .071 & - & -.141 \\
\hline$\Delta \boldsymbol{E}_{\text {act }}$ & .053 & $.373 * *$ & -.006 & .164 \\
\hline$\Delta \boldsymbol{E}_{\boldsymbol{u r}}$ & $.385^{* *}$ & $.312 * *$ & $.294 * *$ & $.449 * *$ \\
\hline$\Delta \boldsymbol{E}_{\boldsymbol{e x p}}$ & - & - & -.059 & - \\
\hline
\end{tabular}

Note: $* *$ Correlation is significant at the 0.01 level (2-tailed).

Table 8. Recommendations of focus target for future renewable energy policy by sector for ASEAN countries from Impact Matrix analysis 


\begin{tabular}{|c|c|c|c|c|c|}
\hline & \multicolumn{5}{|c|}{ Electricity } \\
\hline & $\Delta$ Emix & $\Delta$ Eint & $\Delta E s t r$ & $\Delta E a c t$ & $\Delta E u r$ \\
\hline Cambodia & Focus & Focus & - & Focus & Focus \\
\hline Malaysia & Focus & Potential & - & Careful & Focus \\
\hline Myanmar & Focus & No focus & - & Focus & Focus \\
\hline Philippines & Potential & No focus & - & Careful & Focus \\
\hline Thailand & Focus & No focus & - & Focus & Focus \\
\hline \multirow[t]{3}{*}{ Vietnam } & Potential & No focus & - & Focus & Focus \\
\hline & \multicolumn{5}{|c|}{ Industrial } \\
\hline & $\Delta E m i x$ & $\Delta$ Eint & $\Delta E s t r$ & $\Delta E a c t$ & $\Delta E u r$ \\
\hline Cambodia & Potential & Potential & Potential & Careful & Focus \\
\hline Malaysia & Potential & No focus & Focus & Focus & Focus \\
\hline Myanmar & Potential & No focus & Potential & Focus & Focus \\
\hline Philippines & Careful & No focus & No focus & Focus & Careful \\
\hline Thailand & Focus & No focus & Potential & Focus & Focus \\
\hline \multirow[t]{3}{*}{ Vietnam } & Potential & No focus & Focus & Careful & Focus \\
\hline & \multicolumn{5}{|c|}{ Residential } \\
\hline & $\Delta$ Emix & $\Delta$ Eint & $\Delta E s t r$ & $\Delta E a c t$ & $\Delta E u r$ \\
\hline Cambodia & Potential & Potential & Potential & Careful & Focus \\
\hline Malaysia & No focus & Potential & Careful & Focus & Focus \\
\hline Myanmar & Potential & Potential & No focus & Careful & Careful \\
\hline Philippines & Potential & Potential & Potential & Careful & Careful \\
\hline Thailand & Potential & Focus & Potential & Potential & Focus \\
\hline \multirow[t]{3}{*}{ Vietnam } & Potential & Potential & No focus & Focus & Focus \\
\hline & \multicolumn{5}{|c|}{ Transportation } \\
\hline & $\Delta$ Emix & $\Delta$ Eint & $\Delta E s t r$ & $\Delta E a c t$ & $\Delta E u r$ \\
\hline Cambodia & - & - & - & - & - \\
\hline Malaysia & Focus & Focus & Focus & Focus & Focus \\
\hline Myanmar & - & - & - & - & - \\
\hline Philippines & Focus & Potential & Potential & Careful & Focus \\
\hline Thailand & Focus & No focus & No focus & Focus & Focus \\
\hline Vietnam & - & - & - & - & - \\
\hline
\end{tabular}

